\title{
Electron Microprobe and Synchrotron X-Ray Fluorescence Mapping of the Heterogeneous Distribution of Copper in High-Copper Vineyard Soils
}

Astrid R. Jacobson*1 ${ }^{1}$, Sylvie Dousset ${ }^{2}$, Francis Andreux $^{3}$, Philippe C. Baveye $^{1,4}$

\footnotetext{
${ }^{1}$ Laboratory of Geoenvironmental Science and Engineering, Bradfield Hall, Cornell University, Ithaca, NY 14853-1901, USA.

${ }^{2}$ UMR 5561 Biogéosciences, Centre des Sciences de la Terre et de l’Environnement, Université de Bourgogne, 6 Boulevard Gabriel, 21000 Dijon, France.

${ }^{3}$ UMR 1229 Microbiologie des Sols et Environnement, Centre des Sciences de la Terre et de l’Environnement, Université de Bourgogne, 6 Boulevard Gabriel, 21000 Dijon, France. ${ }^{4}$ SIMBIOS Centre, University of Abertay Dundee, Bell Street, Dundee DD1 1HG, UK.
}

\section{Contents}

- SI: Soil characterization methods and data

- SII: Microscale -spatial distribution of $\mathrm{Cu}$ in a granitic vineyard soil from Beaujolais, France

- SIII: Correlation plots and scanning electron micrographs of particulate organic matter

- SIV: Scanning electron micrographs of POM associated with high Cu signals in the soils

- Pages: S1 - S13

- Table: S1

- Figures: S1-S6 


\section{SI: Soil characterization methods and data}

2 Intact soil columns for use in an herbicide leaching study were collected at the same time and

3 immediately adjacent to the soil blocks described in the main text, following the approach

4 described in Jacobson et al. (22). To avoid unnecessarily duplicating analyses, data collected for

5 the $0-2.5 \mathrm{~cm}$ and $2.5-5 \mathrm{~cm}$ layers in the intact soils columns are reported here (Table S1). These

6 data were collected after the columns had spent 6 months reburied outdoors over pan lysimeters

7 (See reference 22 for details). Only parameters that are unlikely to have changed significantly

8 during that 6-month hiatus are reported. Homogenized soil samples from the 0-20 cm and 0-10

9 cm depth were also collected at the same time and immediately adjacent to the soil blocks. These

10 homogenized samples were air-dried, sieved to $<2 \mathrm{~mm}$ and analyzed as described below for the

$11 \quad 0-2.5 \mathrm{~cm}$ and $2.5-5 \mathrm{~cm}$ soil subsamples.

12 Soil characterization. Subsamples of the $0-2.5 \mathrm{~cm}$ and $2.5-5 \mathrm{~cm}$ layers of the intact soils

columns were air-dried, sieved to $<2 \mathrm{~mm}$, and analyzed to determine their texture (NFX 31-107), pH (NF ISO 10390), carbonate content (NF ISO 10693), total organic C (NF ISO 10694), and total Cu (HF-digest, NFX 31-147; ICP-AES analysis, NF EN ISO 11885) at INRA-Arras. Total soluble $\mathrm{Cu}$ and soluble $\mathrm{Cu}^{2+}$ activity were determined by extraction with $0.01 \mathrm{M} \mathrm{CaCl}_{2}$ according to the method described by Sauvé et al. (S1). Soluble Cu was measured by flame (FAAS) or graphite furnace (GFAAS) atomic absorption spectrometry (Perkin-Elmer 3300, HGA-600). Cu ${ }^{2+}$ activity was measured with a combination Cu-selective electrode (Cole-Palmer).These analyses described in the main article, as well as the earlier data obtained by Jacobson et al. (22) for the 0$20 \mathrm{~cm}$ surface layer (see Table S1) indicate that the granitic soil from Odenas (Bj-150) has a $\mathrm{pH}$ around 5.3. It is coarse-textured with $64 \%$ sand-sized and only $10 \%$ clay-sized particles, and contains relatively little organic carbon (0.5\%). The differences between the soil from Beaujolais (Bj-150) and the soil from Burgundy (VR-450) described in the text, particularly the clay and 
1 organic matter contents, are reflected in their very different cation exchange capacities (CEC) of

$24.8 \mathrm{cmol} \mathrm{kg}^{-1}$ in Odenas soil and $22 \mathrm{cmol} \mathrm{kg}^{-1}$ in Vosne-Romanée soil. As a result, $\mathrm{Cu}$, applied

3 repeatedly, tends to accumulate in the VR soil resulting in a total $\mathrm{Cu}$ concentration 3 times larger

4 than in the $\mathrm{Bj}$ soil. However, because of the lower $\mathrm{pH}$ of the $\mathrm{Bj}$ soil, $\mathrm{pCu}^{2+}$ in this soil is around 5 ,

5 indicating that $\mathrm{Cu}$ is more bioavailable and presumably more harmful to soil microbes (2) than in

$6 \quad$ the VR soil, which has $\mathrm{pCu}^{2+}$ values $>9.0$.

$7 \quad$ Analysis of the soils by polarizing light microscopy showed that the mineralogy of the $\mathrm{Bj}$

8 soil is dominated by feldspars, titanium bearing minerals (rutile, anatase, leucoxene, sphene) and

9 biotite. Therefore, the soil does not contain Cu-rich minerals that might interfere with the 10 interpretation of spectrometric results.

\section{Reference}

13 (S1) Sauvé, S.; McBride, M.; Hendershot, W.H. Ion-selective electrode measurements of copper 14 (II) activity in contaminated soils. Arch. Environ. Con. Tox. 1995, 29, 373-379. 
2 Table S1. Bulk soil characteristics for samples collected immediately adjacent to the intact soil blocks.

\begin{tabular}{|c|c|c|c|c|c|c|c|c|c|c|}
\hline \multirow{3}{*}{ Soil } & \multicolumn{4}{|c|}{ Soil Texture } & \multirow{3}{*}{$\mathbf{p H}$} & \multirow{3}{*}{$\begin{array}{c}\text { carbonate } \\
\% \\
\end{array}$} & \multirow{3}{*}{$\begin{array}{c}\text { TOC } \\
\%\end{array}$} & \multirow{3}{*}{$\begin{array}{c}\text { Cu total } \\
(\mathrm{HF}) \\
\mathrm{mg} \mathrm{kg}^{-1}\end{array}$} & \multirow{2}{*}{\multicolumn{2}{|c|}{ Extractable $\mathbf{C u}$}} \\
\hline & & sand & silt & clay & & & & & & \\
\hline & $\%$ & \multicolumn{3}{|c|}{$\%$ ( of the $<2 \mathrm{~mm}$ fraction) } & & & & & $\mathrm{mg} \mathrm{L}^{-1}$ & $\mathrm{pCu}^{2+}$ \\
\hline \multicolumn{11}{|c|}{ granitic soil } \\
\hline \multicolumn{11}{|l|}{ Bj-150 } \\
\hline $0-2.5 \mathrm{~cm}$ & 13 & 70 & 24 & 5 & 5.8 & $<0.1$ & 1.0 & 176 & & \\
\hline $2.5-5 \mathrm{~cm}$ & 13 & 72 & 23 & 6 & 5.3 & $<0.1$ & 0.7 & 165 & & \\
\hline $0-10 \mathrm{~cm}$ & & & & & & & & 156 & 2.3 & 5.1 \\
\hline $0-20 \mathrm{~cm}$ & 12 & 64 & 26 & 10 & 5.3 & $<0.1$ & 0.4 & 154 & & \\
\hline \multicolumn{11}{|c|}{ calcareous soil } \\
\hline \multicolumn{11}{|l|}{ VR-450 } \\
\hline $0-2.5 \mathrm{~cm}$ & 23 & 29 & 31 & 39 & 8.2 & 23 & 2.7 & 492 & & \\
\hline $2.5-5 \mathrm{~cm}$ & 19 & 26 & 32 & 42 & 8.3 & 21 & 2.2 & 449 & & \\
\hline $0-10 \mathrm{~cm}$ & & & & & & & & 430 & 0.07 & 9.0 \\
\hline $0-20 \mathrm{~cm}$ & 33 & 27 & 30 & 43 & 8.3 & 22 & 1.8 & 417 & & \\
\hline
\end{tabular}



2 from Beaujolais, France

3 Cu distribution maps. In the $30-\mu m$ thick thin section of the Beaujolais soil, $\mu-S X R F$ 4 observations with the $0.3 \mathrm{~mm}$ spot (Fig. S1, center) show that most of the soil has a relatively 5 uniform $\mathrm{Cu}$ concentration near the bottom end of the observed concentration range. This is

\section{SIl: Microscale spatial distribution of $\mathrm{Cu}$ in a granitic vineyard soil} manifested by a very dark to dark blue hue in the $\mu$-SXRF map, corresponding to relative intensities between 0 and 500 counts per second, and appears to be consistent with the moderate $\mathrm{Cu}$ content of this soil. Visual comparison of the map with the scanned picture of the thin section (Fig. S1, left) suggests that this background $\mathrm{Cu}$ concentration is associated with fine-textured constituents, presumably clays and organic matter, dispersed among coarser, sand-size particles. Nevertheless, there are clearly a few areas with very high $\mathrm{Cu}$ contents, identified as red spots, with relative intensities near 2000 counts per second, on the low resolution $\mu$-SXRF map.

Analysis of one of these Cu-rich areas at a finer scale with the capillary-focused 20- $\mu$ m spot size (Fig. S1, right) reveals further details about the spatial distribution of $\mathrm{Cu}$. Especially given the fact that this fine-scale map corresponds to a significantly wider relative intensity range (from 0 to 6000), it is clear that $\mathrm{Cu}$ concentration changes dramatically over very small distances. Literally adjacent 20 - $\mu$ m pixels can be at extreme opposites of the relative intensity spectrum, suggesting thousand-fold differences in Cu concentration.

High-resolution copper distribution maps obtained with the electron microprobe (Figs. S2) demonstrate similar features. In the acidic soil from Beaujolais (Fig. S2), a Cu map of a hotspot near an un-decomposed seed fragment shows $\mathrm{Cu}$ to be distributed in two thin layers, one only a few microns thick, at what appears to be the periphery of the seed. 


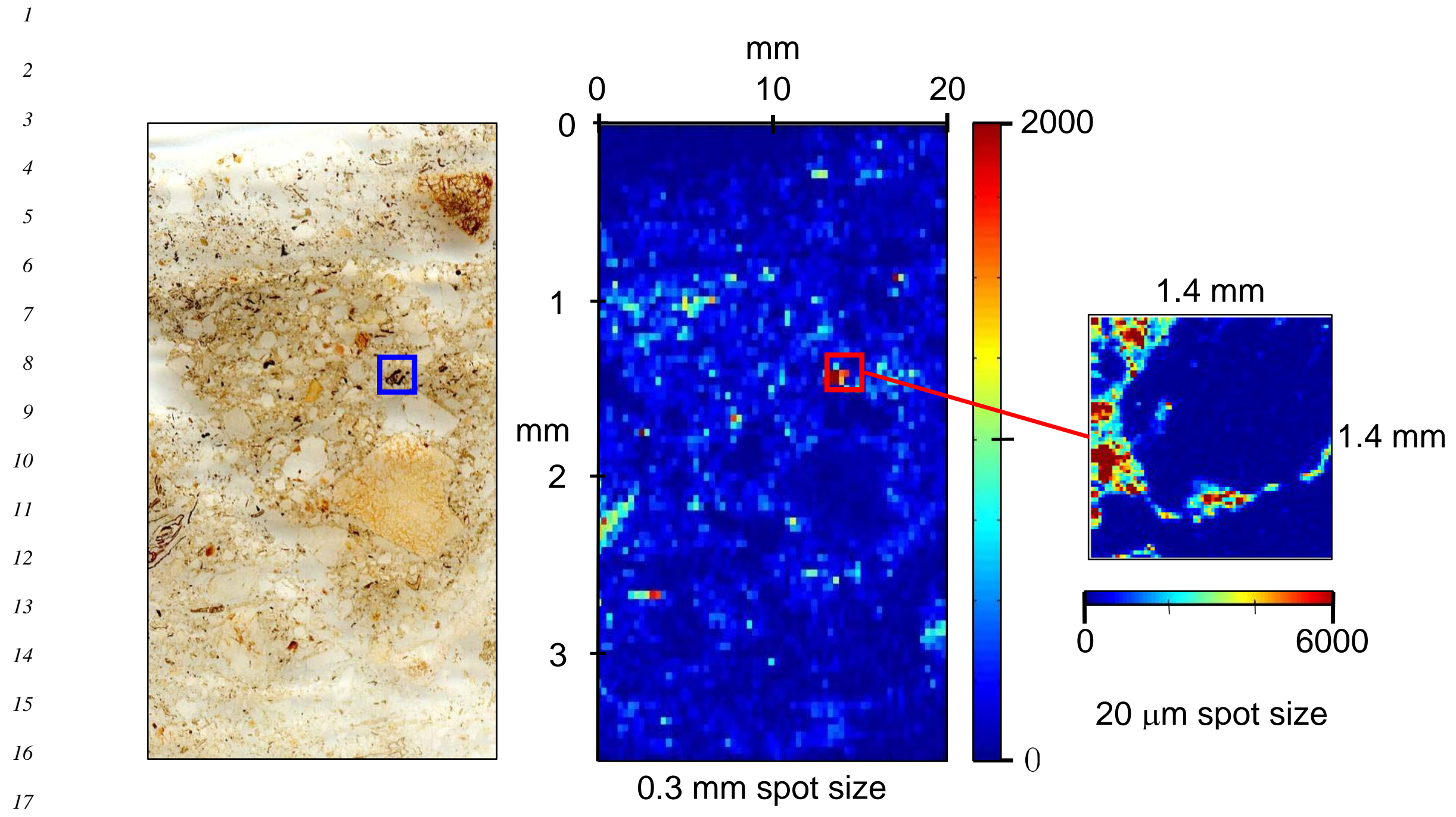

19 Figure S1. Scanned picture of $30-\mu \mathrm{m}$ thick soil thin section of the granitic sandy soil Bj-150 from Beaujolais (left), $\mu$-SXRF map of 20 Cu obtained with a $0.3-\mathrm{mm}$ beam (center) and detailed map obtained with capillary-focused a $20-\mu \mathrm{m}$ beam. 

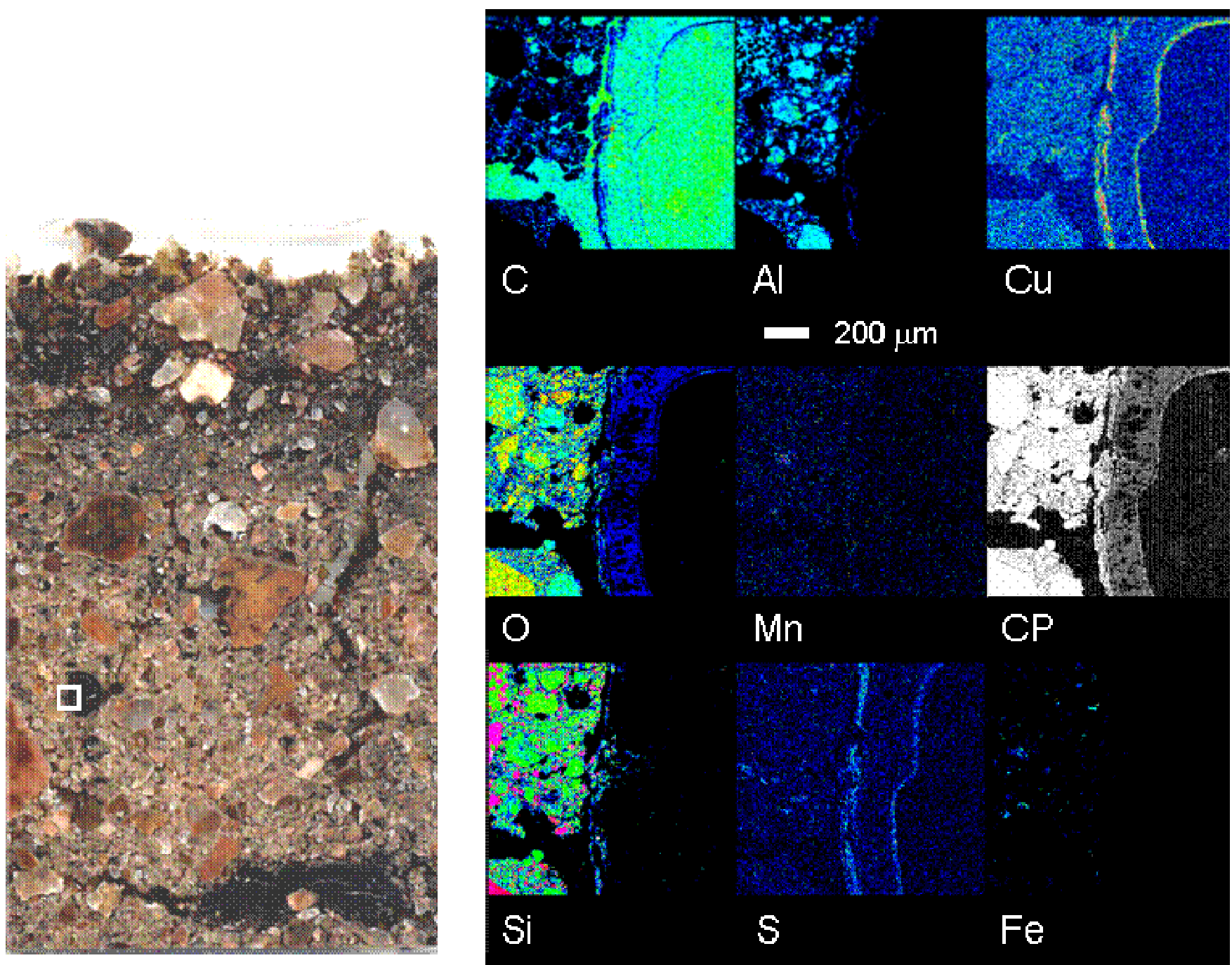

Figure S2: Scanned image of a 1-mm thin section of the $\mathrm{Bj}-150$ soil beside electron microprobe elemental maps of a typical $\mathrm{Cu}$ hotspot (white square in scanned picture, containing part of a grape seed). "CP" stands for compositional backscattered electrons. In the CP map, heavier (higher atomic number) elements are brighter. 
1 Causes of heterogeneous $\mathrm{Cu}$ distribution ( $\boldsymbol{\mu}$-SXRF and microprobe analyses). The acidic

2 soil from Beaujolais has low clay content, of the order of 5-6\% at the surface (Table S1), which

3 appears consistent with the low-resolution $\mathrm{Rb}$ map (Figure S3). The relative intensities are low

4 (dark blue hue) in most of this map. Only at a few spots does the relative intensity exceed 2000

5 counts per second (red hue). In the small area selected for more detailed observation (white

6 square), the low relative intensity for $\mathrm{Rb}$ suggests that the $\mathrm{Cu}$ hotspot observed at this location is

7 not due to the presence of clay minerals. At a higher resolution, this same area is shown to

8 contain a thin clay deposit (turquoise to red pixels). Yet, because the high-intensity pixels in the

$9 \mathrm{Cu}$ map do not overlap with the higher-intensity pixels in the $\mathrm{Rb}$ map, even at this resolution

10 there does not seem to be a clear correlation between the presence of clay minerals and $\mathrm{Cu}$

11 accumulation. For Fe, in the Beaujolais soil (Figure S3), the situation seems relatively clear cut in

12 the low resolution maps, where none of the zones rich in Fe contain much $\mathrm{Cu}$, and vice-versa. In

13 the high-resolution map, visual comparison of the maps does not allow a straightforward 14 conclusion.

15 In the microprobe measurements clay minerals were indirectly identified by $\mathrm{Al}$ and Si scans.

16 In the Beaujolais soil (Fig. S2), some Al and Si appear to surround the outer surface of the seed.

17 Iron is virtually absent from the scan. As in the $\mu$-SXRF maps, there is some Cu co-located with

18 the $\mathrm{Al}$ and $\mathrm{Si}$, but the most intense $\mathrm{Cu}$ signal is seen on the inner and outer surfaces of the seed,

19 where there is no $\mathrm{Al}$ or $\mathrm{Si}$. The element that appears most closely associated with $\mathrm{Cu}$ in the scans

20 is $\mathrm{S}$. The low levels of $\mathrm{O}$ in the seed suggest that $\mathrm{Cu}$ is not associating with sulfate groups, but

21 most likely with sulfides. 

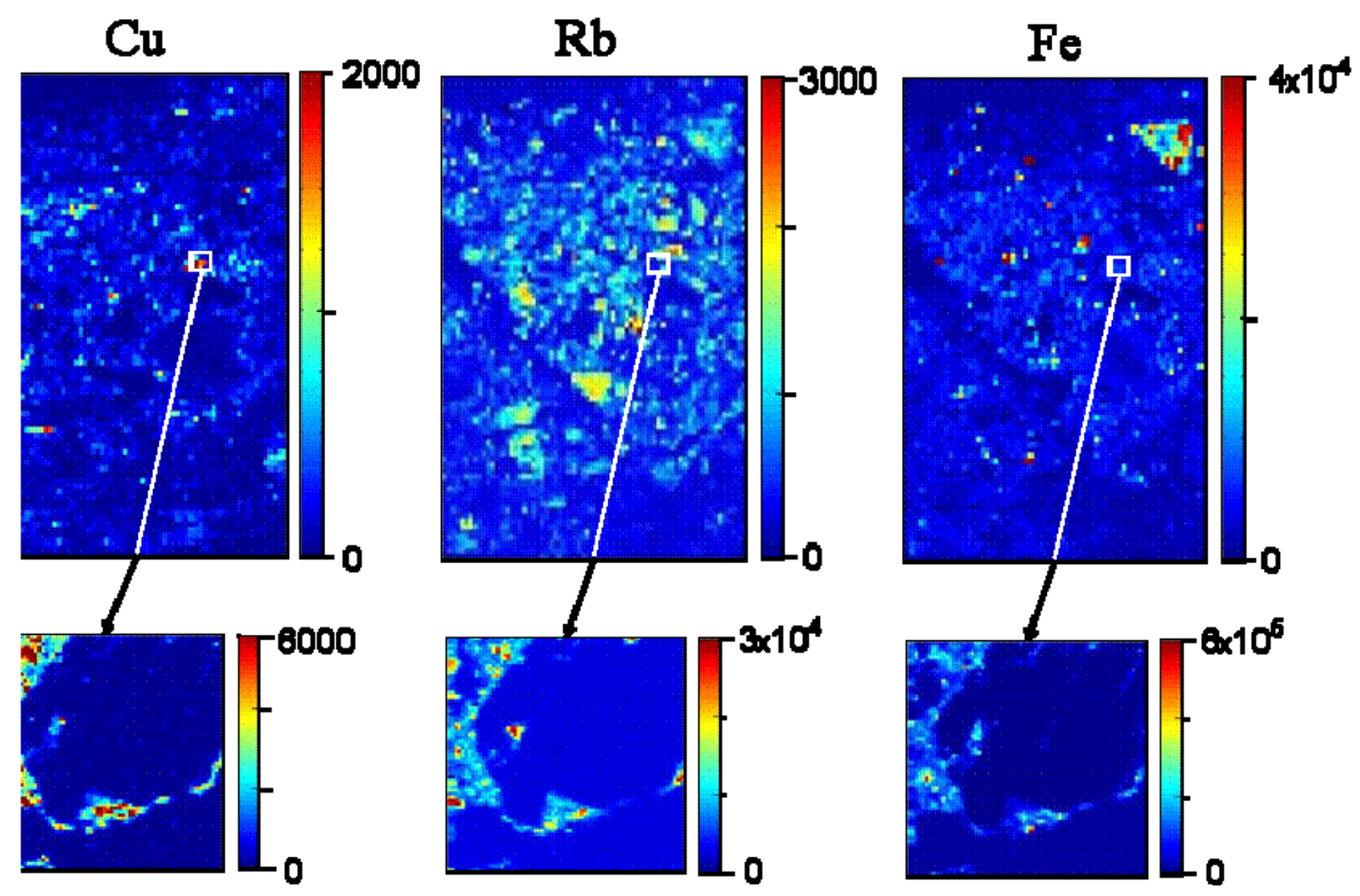

$3 \quad$ Figure S3. $\mu$-SXRF maps of $\mathrm{Cu}, \mathrm{Rb}$ (possible indicator of the presence of clay minerals), and Fe (which could indicate the presence 4 of iron-bearing minerals) in the granitic soil Bj-150. The large maps $(2 \mathrm{~cm} \mathrm{x} 4 \mathrm{~cm})$ were obtained with a 0.3 -mm spot size. The small 5 maps (1 mm x $1 \mathrm{~mm})$ were obtained with a $20-\mu \mathrm{m}$ spot size. 


\section{SIII: Correlation plots}

This section contains the pixel by pixel correlation plots for $\mathrm{Cu}$ vs. $\mathrm{Rb}$ and $\mathrm{Cu}$ vs $\mathrm{Fe}$ at two resolutions ( $0.3 \mathrm{~mm}$ pixel diameter and $20 \mu \mathrm{m}$ pixel diameter) that are described in text for the calcareous soil from Burgundy (Fig S4C-D and Fig. S5C-D). The correlation plots for the granitic soil from Beaujolais are also depicted (fig. S4A-B and Fig. S5A-B). The scatter in the correlation points is just as great, and the correlation coefficients as poor, as described in the text 7 for the soil from Burgundy $\left(\mathrm{R}^{2}<0.05\right)$. Removing the high-intensity Fe data points from the plots, to mask $\mathrm{Cu}$ associated with Fe-bearing minerals, did not improve the correlations.
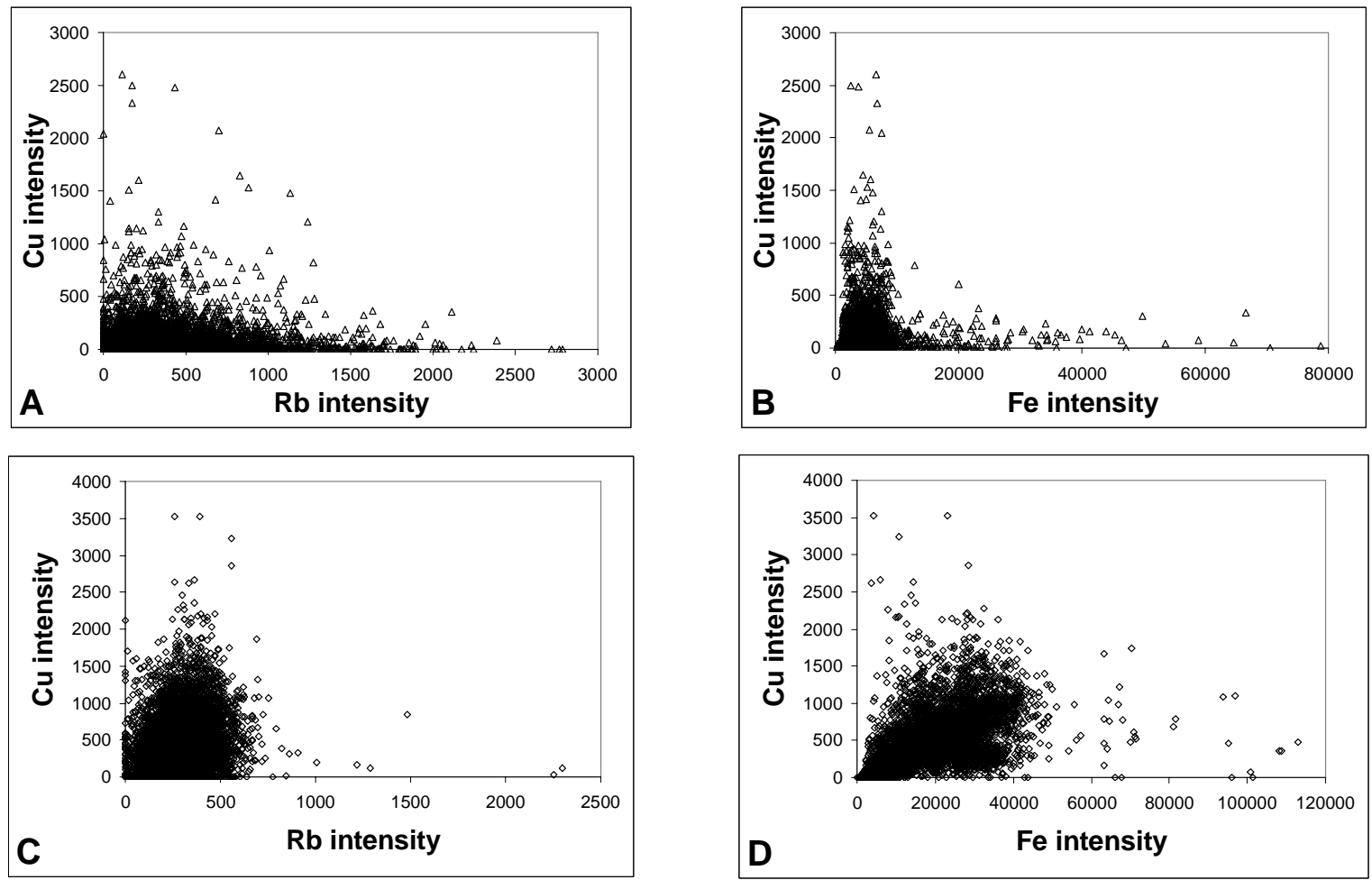

11 Figure S4. Pixel by pixel correlation plots of relative intensities of $\mathrm{Cu} v \mathrm{vs}$. $\mathrm{Rb}$, and $\mathrm{Cu}$ vs. Fe for $2 \mathrm{~cm} \times 4 \mathrm{~cm}$ areas of soil. Each pixel corresponds to a $0.3 \mathrm{~mm}$ diameter data point. A and B: Granitic soil from Beaujolais. C and D: Calcareous soil from Burgundy. 

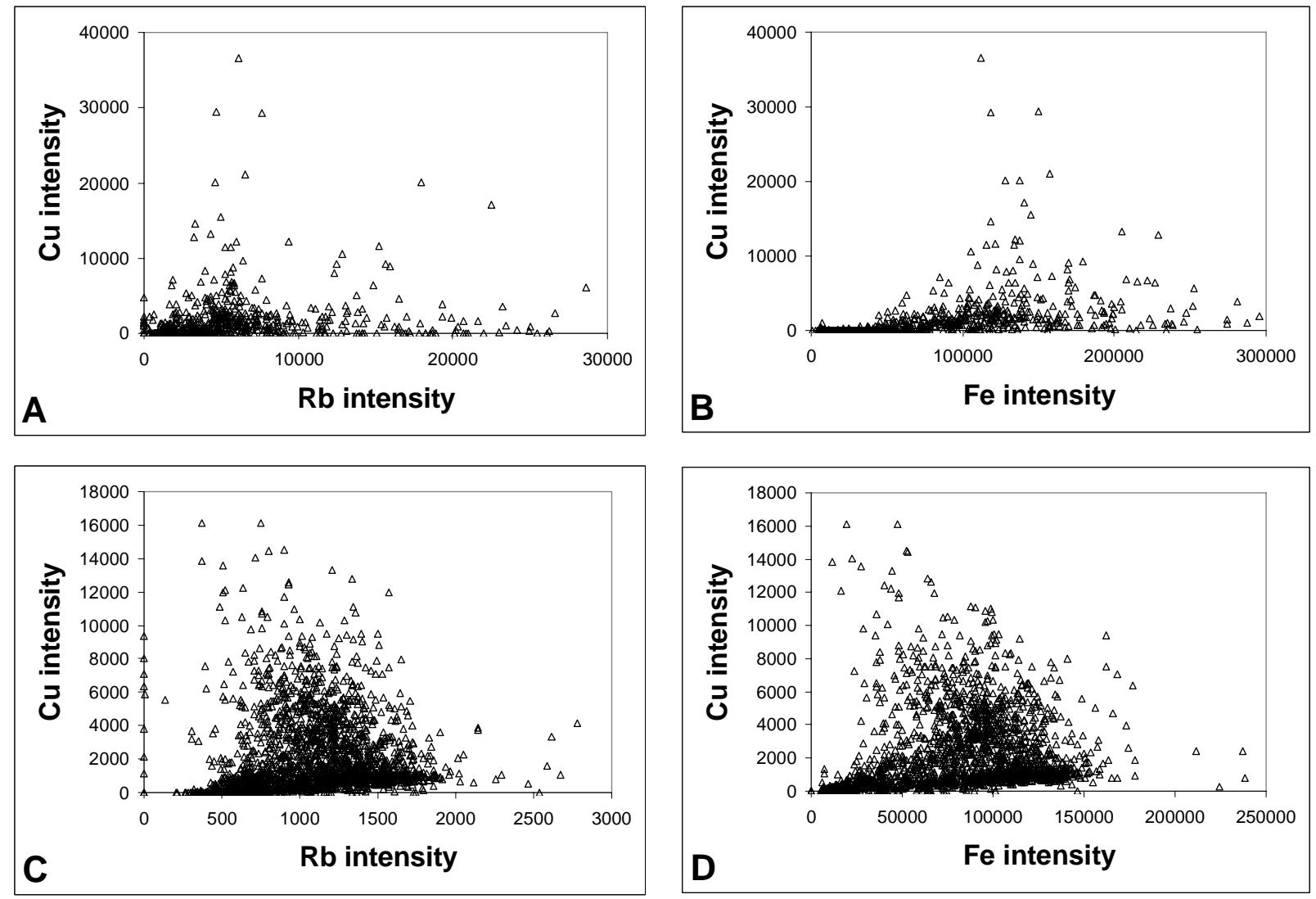

3

Figure S5. Pixel by pixel correlation plots of relative intensities of $\mathrm{Cu}$ vs. $\mathrm{Rb}$ and $\mathrm{Cu}$ vs. Fe over a $1-\mathrm{mm}^{2}$ area of soil. Each pixel corresponds to a $20 \mu \mathrm{m}$ diameter data point. A and B: Granitic soil from Beaujolais $\mathbf{C}$ and D: Calcareous soil from Burgundy 


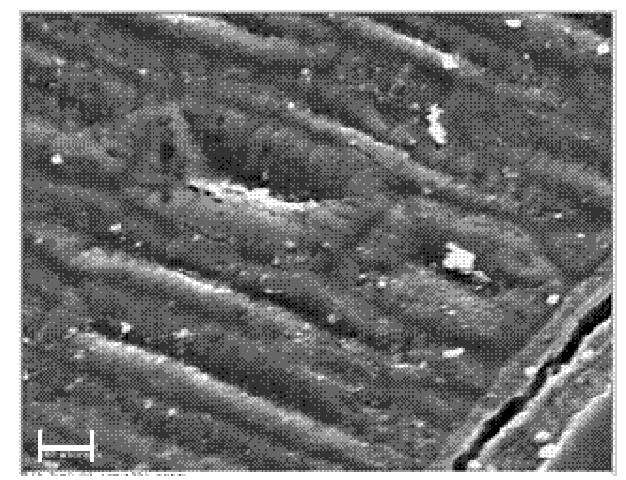

100 microns

A.

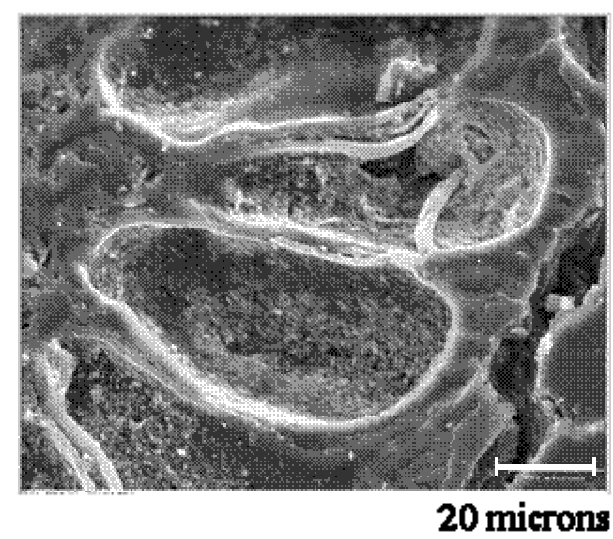

B.

$3 \quad$ Figure S6. SEM images of typical POM plant fragments, namely a leaf (A) and a seed (B), $4 \quad$ which are found in the soils and are associated with high $\mathrm{Cu}$ counts. 